\title{
Silastic Band Migration: An Unusual Complication Following Vertical Banded Gastroplasty
}

Currently, vertical banded gastroplasty is one of the procedures of choice for the treatment of morbid obesity [1,2]. It is a restrictive technique, associated with a rapid weight loss that is fairly well maintained over time. However, the price paid for these results is relatively high, if complications and the additional surgical procedures needed to resolve them are considered.

A 34-year-old woman, who 4 months previously had undergone vertical banded gastroplasty for the treatment of morbid obesity, was admitted to our hospital, complaining of epigastric pain during the last 5 days and "coffee-ground" vomiting in the previous 24 hours. Laboratory findings revealed mild leukocytosis and irondeficiency anemia, while the radiographic examination showed no gastric dilatation or pneumoperitoneum. Upper endoscopy revealed one of the most unusual complications of vertical banded gastroplasty: migration of the band. The silastic band was located just below the cardia, along the lesser curvature in the upper third of the stomach, and it was removed using rat-tooth forceps (Figures $\mathbf{1 - 3}$ ). The successful endoscopic attempt to overcome this complication avoided a surgical inter-

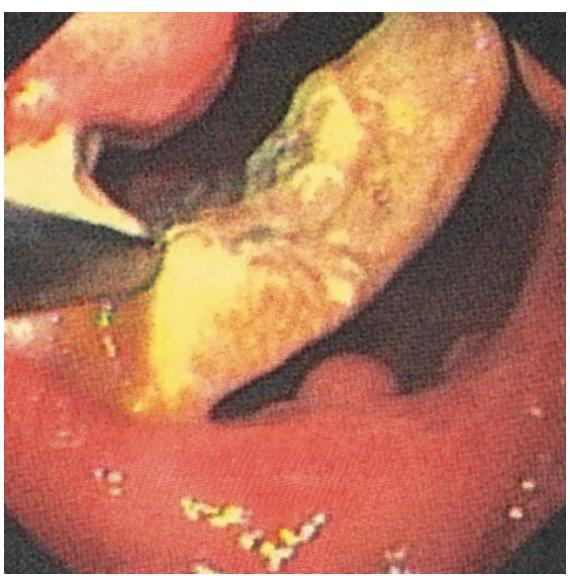

Figure 1 Upper endoscopy showed migration of the silastic band, one of the most unusual complications of vertical banded gastroplasty. vention. A control endoscopy 2 weeks later revealed ulceration of the area, and the patient was completely well at a 3month follow-up.

Complications encountered during follow-up after vertical banded gastroplasty $[2,3]$, include stenosis (20\%), staple-line disruption (11\%), incisional hernia (13\%), severe esophagitis (7\%), and band migration $(1.5 \%)$. The majority of these patients require one or more corrective procedures, including re-operation [4]. These complications should be borne in mind with regard to patients who have undergone this technique for the treatment of morbid obesity.

\section{Froilán Torres, J. M. Suárez,} M. D. Martín, P. Castillo, D. Hervías, J. M. Segura

Department of Gastroenterology, La Paz University Hospital, Madrid, Spain

\section{References}

${ }^{1}$ Suter M, Jayet C, Jayet A. Vertical banded gastroplasty: long term results comparing three different techniques. Obes Surg 2000; 10: 41 -46

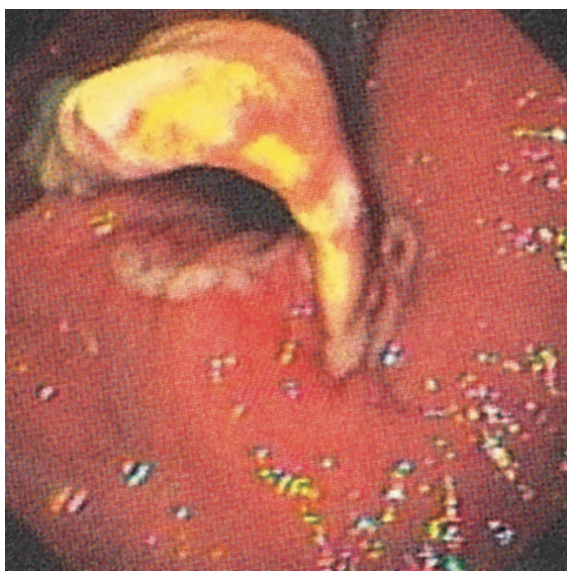

Figure 2 With retroflexion, the silastic band could be seen just below the cardia.
2 Sugerman HJ, Kellum JM Jr, DeMaria EJ, Reines HD. Conversion of failed or complicated vertical banded gastroplasty to gastric bypass in morbid obesity. Am J Surg 1996; 171: 263-269

${ }^{3}$ Bogokowsky H, Slutzki S, Waron M et al. Vertical banded gastroplasty for the treatment of morbid obesity. J Clin Gastroenterol 1988; 10: 655-658

${ }^{4}$ Wolf AM, Kuhlmann HW. Reoperation due to complications after gastric restriction operation. Obes Surg 1995; 5: $171-178$

\section{Corresponding Author}

\section{Froilán Torres, M.D.}

Department of Gastroenterology

La Paz University Hospital

C/Plaza del Pueblo 16

Colmenar Viejo 28770

Madrid

Spain

Fax: + 34-9157-50251

E-mail: mfroilant@medynet.com

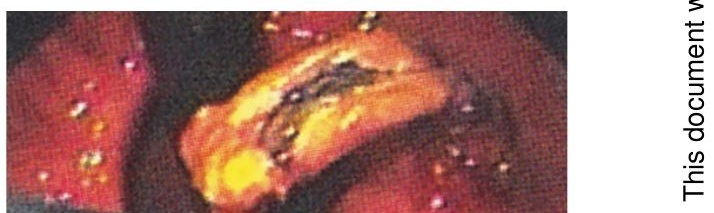

